\title{
THE ROLES OF THE ONLINE ENVIRONMENT IN SCHOOL-FAMILY COMMUNICATION
}

\author{
Otilia Clipa \\ Stefan cel Mare University, Romania \\ Valentina Juravle \\ Stefan cel Mare University, Romania
}

\begin{abstract}
The study focused on the issue of increasing communication efficiency between school and family using the online environment. The aim of the study is to evaluate to what extent the online communication environment can improve the process of communication between school and family. The study is quantitative, based on the questionnaire method. Two questionnaires were distributed in the online environment to teachers and parents. Both questionnaires showed that the communication relationship between school and family is not very efficient; this being the reason for hypothesizing that online communication between parents and teachers could be a solution to this issue. In this context, both investigated samples foresee the benefits of a communication relationship between school and family in the online environment and do not consider that information transmitted in this way differs from that transmitted in a direct conversation.
\end{abstract}

Keywords: Communication, School, Family, Efficiency, Online Communication.

\section{Introduction}

Communication has always been a subject of interest for many disciplines, including philosophy. Ever since antiquity, philosophers across the world have reflected on communication, discovering its role in life, especially in social life. If we could summarize the whole history of philosophy, we could assert that in antiquity, communication ontology concerns were predominant. Communication is everywhere, and the field of communication has become vast. All human activities, individual or collective, revolve around information that is sent, received or analysed. Communication is part of action and reflection, just as currency is part of the economy (Zemor, 2003).

Digital competence is the most recent concept describing technologyrelated skills. During recent years, several terms have been used to describe 
the skills and competence of using digital technologies, such as ICT skills, technology skills, information technology skills, $21^{\text {st }}$ century skills, information literacy, digital literacy and digital skills. These terms are also often used as synonyms; e.g. digital competence and digital literacy (Adeyemon, 2009; Almås \& Krumsvik, 2008; Krumsvik, 2008; Petersson, 2018). Sometimes the terms are narrow, e.g., Internet skills, referring only to a limited area of digital technology, while some of them widen the content to media and literacy, e.g., media literacy skills or digital literacy (Clipa \& Colomeischi, 2013; Ilomäki, Kantosalo, \& Lakkala, 2011; Ottestad, 2008; Petersson, 2018).

Students interact collaboratively with teachers and technology. Computers deliver and mark lessons, while the teacher acts as a facilitator and mentor (Bennett, 2002; Dooling, 2000).Furthermore, educators have "to accept changes...in [their] interactions...with students and they [have] to support students as their roles change, too" (Harris, 2002).

People not only socialize online, but they make use of the Internet in seeking information, exchanging advice and making decisions. Americans may now have only one or two extremely close relationships, but dozens of core and significant ties in the "networked" community (Boase et al. 2006).

In the circumstances, both the theoretical and practical studies will aim at focusing on presenting all the important characteristics which define the family environment, as well as those defining the school environment.

We chose to approach this issue because we wanted to identify as many relevant aspects as possible in this context, as well as wanting to apply, in the educational context, the new ideas from specific literature that already existed in this area of study.

All these basic considerations regarding the importance of this subject drew the interest of many specialists in this area of study, which is not recent, but is a part of human communication research and analysis, namely that of antisocial deviations. Cornell University offers a definition that works, but seems somewhat limited and dated as well: "Digital literacy is the ability to find, evaluate, utilize, share, and create content using information technologies and the Internet"(Melnikova et al., 2017; Olofsson, Lindberg, Fransson, \& Hauge, 2015; Vanderlinde \& van Braak, 2010).

This isn't wrong rather it focuses too much on technology and "the Internet". Literacy cannot be about the forms unless we're talking about form literacy. Digital tools exist for accessing information and finding better information'access, socializing thinking and spreading ideas; connecting and contributing to digital communities you care about ( $\underline{\text { Heick}}$, 2015; Petersen, 2014). In a study on the role of the Internet in families, it was found that $33 \%$ of Internet users said that the Internet had improved 
their connections to friends "a lot", and $23 \%$ said Internet communication had increased the quality of their communication with family members by a similar amount. Young people in particular took advantage of the social side of the Internet. Nearly half (49\%) of 18-29 year olds said that the Internet had improved their connections to friends a lot. On the other hand, 19\% of employed Internet users said that the Internet had increased the amount of time they spent working at home (Eynon\& Helsper, 2014).

Some studies focus on one-stop targeting, in which the seeds are selected by selecting the highest in-degree nodes and randomly selecting one of their neighbours (Kim et al., 2015). These studies hypothesized that the online social network is a strongly connected component, in which every node can gain access to the rest of the nodes in the network (Shakya et al., 2017).

In a study done in 2004, Boase and his colleagues (2006) found that even with the flourishing of the Internet, people still commonly communicated with their social ties in traditional ways, in addition to the use of the Internet for social communication. They found that in-person encounters were most widely used, followed by landline phone, cell phone, email, and IM communication. Far from being a medium that connects weaker ties in superficial ways, email was used more for maintaining core rather than significant ties.

Core ties are more often relied upon for seeking help than significant ties. But significant ties are composed of people more than acquaintances and can, at times, become important players in help-seeking. Boase and his colleagues (2006) found that people not only socialized online, but they incorporated the Internet into seeking information, exchanging advice, and making decisions. Americans may now have only one or two extremely close relationships, but dozens of core and significant ties in the "networked" community. Four years later in 2008, a similar study on social isolation and new technology found that in-person contact remained the dominant means of communication with core members; emails, instant messaging, and social networking websites supplemented this dominant mode of communication (Hampton et al. 2009). In a study done in 2004, Boase and his colleagues (2006) found that even with the flourishing of the Internet, people still commonly communicated with their social ties in traditional ways, in addition to the use of the Internet for social communication. They found that in-person encounters were most widely used, followed by landline phone, cell phone, email, and IM communication. Far from being a medium that connects weaker ties in superficial ways, email was used more for maintaining core rather than significant ties. Core ties are more often relied upon for seeking help than significant ties. But significant ties are composed of people more than acquaintances and can, at times, become important players in help-seeking. Boase and his colleagues (2006) found 
that people not only socialized online, but they incorporated the Internet into seeking information, exchanging advice, and making decisions. Americans may now have only one or two extremely close relationships, but dozens of core and significant ties in the "networked" community. Four years later in 2008, a similar study on social isolation and new technology found that in-person contact remained the dominant means of communication with core members; emails, instant messaging, and social networking websites supplemented this dominant mode of communication (Hampton et al. 2009).

This paper considers a case study on making communication more efficient between school and family, using the online environment.

\section{Methodology}

\section{The aim of the study}

The study aims to assess to what extent the online environment can improve the school-family communication process.

The objectives of our study were:

1. The analysis of the communication relationship between school and family;

2. Identifying the extent to which the online environment influences school-family communication;

3. Identifying the most appropriate communication channels between school and family;

4. Assessing the extent to which the improvement of the schoolfamily communication relationship through the online environment determines the improvement of the pupils' school performances.

\section{Research hypothesis}

The present study starts from the following hypothesis:

1. It is assumed that the online environment could improve the schoolparents' communication frequency for parents.

2. It is assumed that there are differences regarding the preferences for the communication environment between parents and teachers.

3. It is assumed that there is a positive correlation between online communication between school and family and the improvement of the pupils' grades. 


\section{Participants and procedure}

There were 120 respondents taking part in this research, 60 parents and 60 teachers. The two investigated samples had different ages and genders. Thus, regarding the gender a perfect proportionality was kept between mothers and fathers. However, the teachers did not have the same homogeneity, the female subjects being numerically superior. The ages of the parents who took part of the study were between 29 and 49, with an average of 38.13 years. The teachers' ages were relatively similar to the parents, between 27 and 52, with an average of 37.23 years.

The present study is quantitative based on the questionnaire method. This was distributed online. It was considered to be easier to share the questionnaire online, on 'iSondaje.ro'asit allows creating your own survey free of charge. The preliminary results could be seen immediately after the questionnaire was filled in by the respondents.

The data were also exported into Excel and SPSS. Similar toother methods of questionnaires dissemination, the online surveys were used on a large scale, thus receiving enough feedback can take a while, and the results can sometimes be irrelevant or errors may occur. In this study, only one questionnaire was applied for two different groups of subjects, so that the items' design was slightly different too, depending on the studied sample.

\section{Results}

In order to conduct the present research, education, age and place of origin were not taken into consideration as sample selection criteria. The data were collected through the Internet; all the questionnaires were delivered to different groups accessed by the target population on Facebook, then processed in SPSS. According to the literature, the samples size should be calculated with a $95 \%$ probability with an acceptable statistical error of 5\%. The analysis of the two applied questionnaires begins with an assessment of the school-family relationship. In this context, from the parents' point of view, as presented in the table below, most of them, namely $43.3 \%$ assess the relationship with their children's school as a good one. It may be seen though that there is $6.7 \%$ of parents have no relationship to the school, describing it as being non-existent.

The opinions of the teachers to the same item are relatively different, most of the respondents, namely, 33.3\% describing the school-family relationship as being distant. Another difference is the fact that $23.3 \%$ of the parents describe the relationship with the school as very good while only $16.7 \%$ of the teachers chose this answer. 
Thus, teachers think that the relationship between school and family is more distant than the parents see it.

The next item assessed the frequency of the contact parents have with school, from their point of view. In this context, as it can be noticed below, most of the respondent parents (33.3\%) claimed that they keep in touch weekly with school and their children's teachers. Forthe same item, only $3.3 \%$ of the parents asserted that they contact the school and teachers annually or never.

The teachers' opinion is different regarding this item too, with $26.7 \%$ asserting that parents get in touch with school every 2-3 weeks. Also, unlike the $3.3 \%$ of parents who claim to be in contact with school each year, the teachers claim that there are more than $10 \%$ of them.

The third item from both questionnaires focused on increasing the schoolfamily communication frequency through online communication. In this context, $86.7 \%$ of the questioned parents agreed to this idea. Within this item, the teachers' opinions did not differ much from those of the parents, so that $76.7 \%$ of the questioned teachers answered affirmatively. The similarity of the teachers' and parents' answers can be noticed too in the correlation presented below (Table 1).

Table 1. Correlation of parents' and teachers' opinions

\begin{tabular}{|l|c|c|}
\hline Correlations & Parents' opinion & Teachers' opinion \\
\hline Parents' opinion & 1 & -.312 \\
\hline Teachers' opinion & -.312 & 1 \\
\hline
\end{tabular}

There was a discussion on how online communication could improve the school-family relationship. In this context, $80 \%$ of the parents said that this online communication can improve the relationship with the school. In this case too, the teachers' opinion was relatively similar to the parents', so that $80 \%$ and $76.7 \%$ of them, respectively, asserted that they agree that online communication can improve the relationship with the parents.

Through this item, the first suggested hypothesis can be verified, by which it is supposed that the online environment would increase the frequency of the school-family communication for the parents. Thus, analysing the answers of both samples, it can be asserted that the hypothesis is confirmed, taking into account that more than $70 \%$ of the subjects answered affirmatively to this item. This hypothesis can be validated also by the correlation of the parents' and teachers' answers to the same question.

On this item, the subjects' opinions were different according to gender, so that it can be noticed in the table below, that the male teachers are more 
optimistic regarding the improvement of the parents-school relationship with this type of communication. We tried to identify the most appropriate way to communicate online. In this case, most respondent parents, namely $33.3 \%$ considered WhatsApp as the most appropriate, followed closely by Facebook. The teachers' opinions were very different regarding this item. Thus, most of the respondents, namely $50 \%$ of them considered that the most adequate formof online communication with the parents is through a platform specially created for such discussions, the next method chosen in this context being represented by e-mail.

The second hypothesis, which assumes that there are differences in the preference for the communication environment between parents and teachers, is confirmed by this item, a fact which is also confirmed by the results presented above, indicating obvious differences between the two investigated samples.

The next item assesses the respondents' opinion regarding the online sending of messages, namely the idea according to which we can send the same information online as in a direct communication. In this context, most of the parents, specifically $73.3 \%$, agreed to this assertion. The opinion of the teaching staff was not much different within this item either, $80 \%$ of the teachers believing that they could also transmit the same information in an online environment.

Teachers' beliefs, practices and attitudes are important for understanding and improving educational processes. They are closely linked to teachers' strategies for coping with challenges in their daily professional life and to their general well-being, and they shape students' learning environment and influence student motivation and achievement. Furthermore, they can be expected to mediate the effects of job-related policies - such as changes in curricula for teachers' initial education or professional development - on student learning. TALIS examines a variety of beliefs, practices and attitudes which previous research has shown to be relevant to the improvement and effectiveness of schools (OECD, 2018). The following table (Table 2) shows the negative correlation between parents' and teachers' opinion about the utility of Internet and technology in education.

Furthermore, teachers who readily integrate technology into their instruction are more likely to possess constructivist teaching styles. Evidence suggests there is a parallel between a teacher's student-centred beliefs about instruction and the nature of the teacher's technologyintegrated lessons. This connection between the use of technology and constructivist pedagogy implies constructivist-minded teachers maintain dynamic student-centred classrooms where technology is a powerful learning tool(Judson, 2006). 
Table 2. Correlation between parents' and teachers' opinion

\begin{tabular}{|l|l|c|c|}
\hline \multicolumn{2}{|l|}{} & Parents' opinion & Teachers' opinion \\
\hline \multirow{4}{*}{ Parents' opinion } & Pearson Correlation & 1 & -.159 \\
\cline { 2 - 4 } & Sig. (2-tailed) & & .003 \\
\cline { 2 - 4 } & N & 60 & 30 \\
\hline \multirow{3}{*}{ Teachers' opinion } & Pearson Correlation & -.159 & 1 \\
\cline { 2 - 4 } & Sig. (2-tailed) & .003 & 30 \\
\cline { 2 - 4 } & N & 60 & \\
\hline
\end{tabular}

Some forms of technology will not necessarily yield comparable results in every educational environment. Technology is not used in isolation for teaching and learning, and the impact of technology on education is largely determined by the educational setting established. To be successful, a teacher attempting to integrate technology into a classroom environment must consider factors such as: administration, teacher, student and parental attitudes towards technology; the educator's teaching style and philosophy; the subject and concepts taught; and the learning styles of the students (Tolmie, 2001).

Next, the study aimed to calculate the extent to which permanent online communication with school can determine pupils' school success. Thus, $40 \%$ of the parents consider that an online communication relationship can moderately improve performance in school. The respondent teachers think the same, but with a higher percentage, namely, 46.7\%. As a result of the data obtained for this item, the hypothesis according to which there is a positive correlation between school-family communication and the improvement of the pupils' grades is validated. The study further assessed the extent to which the online communication environment really represents a solution for maintaining an effective school-family relationship. Regarding this item, most of the surveyed parents, namely $46.7 \%$, are almost entirely in agreement with the idea that online communication is really a solution to maintaining an effective relationship with the school. The teachers' opinion was not much different from that of the parents, so $40 \%$ of them also argued that they are almost entirely in agreement with the fact that online communication is really a solution for maintaining an effective relationship with the parents. 


\section{Discussion}

Both questionnaires confirmed the fact that the communication relationship between school and families is not a very efficient one, which formed the premise according to which online communication between parents and school could be a solution. In this context, both surveyed samples said that the online environment can be an important and good opportunity both for the school and pupils, namely, for their academic performances.

Even though the same questionnaire was applied to both samples, there were differences of opinion between parents and teachers, the most important of them relating to the item for identifying the most appropriate online communication channels (Ahrens et al., 2015; Olofsson et al., 2015). However, both surveyed groups see the benefits of a school-to-family communication relationship in the online environment, and do not believe that the information transmitted in this way would be different from that transmitted in a direct conversation (Ivan \& Duduciuc, 2011).

It is therefore recommended to maintain a communication relationship between school and family in the online environment for any kind of situation. Of course, direct communication is also very important, but in the absence of resources to maintain an effective direct communication relationship, encouraging the promotion of online communication is recommended.

\section{Conclusions}

The idea of school-family communication involves a partnership. Thus, the school-family partnership becomes the most accessible and beneficial. All the teachers are in need of important information regarding the pupils' family circumstances, as well as regarding their socio-affective status at home.

An efficient school relates to the pupil, by valuing and respecting his or her identity within the family, recognizing its importance and drawing on it in the teaching process with all the educative resources of the society which it identifies, involves and actively uses. There is also a complex network of relationships within the school, which are important in influencing pupils' education, both positively and negatively (Krumsvik, 2008; Petersson, 2018; Rime, 2007).

Currently, the dimensions of this relationship are more encompassing as a result of the widening of the collaboration concept towards communication through cooperation, and more recently, through the partnership concept 
which comprises everyone and expresses a certain positive and democratic approach towards educative relations.

An effective school works in partnership with the student, respecting his or her identity with the family, recognizing its importance and seeking to always draw into the teaching process all the society educational resources which it identifies, involves and even actively uses. There are situations where communication barriers between teachers and parents arise, either from lack of experience or of team spirit or being unable to find the time to collaborate with school.

This paper has shown that the online environment is a very good media for communication and for maintaining an effective relationship between school and family, so this type of communication is encouraged, online communication being not much different to direct communication and which can have many benefits and advantages, from which both parents and teachers can benefit. For the pupils' well-being, it is recommended that such barriers should be removed, either through the parents' or teachers' efforts.

\section{References}

Adeyemon, E. (2009). Integrating Digital Literacies into Outreach Services for Underserved Youth Populations. The Reference Librarian, 50, 85-98. 10.1080/02763870802546423.

Ahrens, A., Zaščerinska, J., Melnikova, J., Ramar, H., Clipa, O., \& Andreeva, N. (2015). Use of Webinars in Higher Education: A Comparative Study of Educators' Experience. III International Scientific Practical Conference "Trends in Science and Studies under Conditions of Globalisation" Scientific Articles: Applied Research in Studies and Practice, $11,22-30$.

Almås, A. \& Krumsvik, R. (2008). Teaching in Technology-Rich Classrooms: Is There a Gap between Teachers' Intentions and ICT Practices?Research in Comparative and International Education, 3. 10.2304/rcie.2008.3.2.103.

Bennett, F. (2002). The future of computer technology in K-12 education. Phi Delta Kappan, 83(8), 621-626. Retrieved 12 October 2002, from Academic Search Elite database.

Boase, J., Horrigan, J., Wellman, B., \& Rainie, L. (2006). The strength of internet ties. Washington, DC: Pew Internet \& American Life Project. Retrieved from http://www. pewinternet.org/Reports/2006/The-Strength-of-Internet-Ties.aspx.

Boase, J., Horrigan, J., Wellman, B., \& Rainie, L. (2006). The strength of internet ties. Washington, DC: Pew Internet \& American Life Project. Retrieved from http://www. pewinternet.org/Reports/2006/The-Strength-of-Internet-Ties.aspx.

Clipa, O., Colomeischi, A. A., Schipor, D. M., \& Cramariuc, G. (2014). Students' Perceptions upon ICT in University Training Process, Elearning and Software for Education, 109-114.

Clipa, O. \& Colomeischi A. A. (2013). University Teaching - The Use of Social Media in Teacher Education, in Web 2.0 in Education and politics. The Social Media Revolution, ed. Lambert Academic Publishing, Germany, 2013, pp. 187-203. 
Dooling, J. (2000). What students want to learn about computers? Educational Leadership, 58(2), 20-24.

Eynon, R.\&Helsper, E. (2014). Family dynamics and internet use in Britain: What role do children play in adults' engagement with the internet? Information, Communication \& Society, 18(2), 156-171. DOI: 10.1080/1369118X.2014.942344, Taylor \& Francis.

Harris, S. (2002). Innovative pedagogical practices using ICT in schools in England. Journal of Computer Assisted Learning, 18(4), 449-458.

Heick, T. (2015). The Definition of Digital Literacy. http://www.teachthought.com/ pedagogy/literacy/the-definition-of-digital-literacy/.

Ilomäki, L., Kantosalo, A., \& Lakkala, M. (2011). Whatis digital competence?https://tuhat. helsinki.fi/portal/files/48681684/Ilom_ki_etal_2011_What_is_digital_competence.pdf

Ivan, L. \& Duduciuc, A. (2011). Comunicare nonverbala si constructii sociale. București: Editura Tritonic.

Judson, E. (2006). How Teachers Integrate Technology and Their Beliefs About Learning: Is There a Connection? Journal of Technology and Teacher Education, 14(3), 581-597. Waynesville, NC, USA: Society for Information Technology \& Teacher Education. Retrieved 17 June 2019 from https://www.learntechlib.org/ primary/p/6046/.

Kim, D. A., Hwong, A. R., Stafford, D., Hughes, D. A., O’Malley, A. J., Fowler, J. H., \& Christakis, N. A. (2015). Social network targeting to maximise population behaviour change: A cluster randomised controlled trial. The Lancet, 386(9989), 145-153.

Krumsvik, R. (2008). Situated learning and teachers' digital competence. Education and Information Technologies,13, 279-290. 10.1007/s10639-008-9069-5.

Melnikova, J., Zascerinska, J., Ahrens, A., Hariharan, R,Clipa, O., Sawinska-Milewska, D. \&Andreeva, N. (2017). A comparative study of educators' views on advantages and disadvantages of open educational resources in Higher Education, Society. Integration. Education. Proceedings of the International Scientific Conference, vol. 1, pp. 294-304. http://journals.ru.lv/index.php/SIE/article/view/2362.

OECD, (2018). Teaching and Learning International Survey.https://www.oecd.org/ berlin/43541655.pdf.

Olofsson, A. D., Lindberg, J. O., Fransson, G., \& Hauge, T. E. (2015). Uptake and use of digital technologies in primary and secondary schools - A thematic review of research. Nordic Journal of Digital Literacy, 6(4), 103-121.

Ottestad, G. (2008). Schools as digitally competent organizations: Developing organisational traits to strengthen the implementation of digital founded pedagogy. International Journal of Technology, Knowledge and Society, 4(4), 10.

Petersen, A. (2014). Teachers' perceptions of principals' ICT leadership. Contemporary Educational Technology, 5(4), 302-315.

Pettersson, F. (2018). Education and Information Technology, 23, 1005. https://doi. org/10.1007/s10639-017-9649-3.

Rime, B. (2007). Comunicarea socială a emoțiilor. Bucuresti: EdituraTrei.

Shakya, H. B., Stafford, D., Hughes, D. A., Keegan, T., Negron, R., Broome, J., \& Christakis, N. A. (2017). Exploiting social influence to magnify population-level behavior change in maternal and child health: Study protocol for a randomized controlled trial of network targeting algorithms in rural Honduras, BMJ Open, 7(3), $1-13$. 
Tolmie, A. (2001). Examining learning in relation to the contexts of use of ICT. Journal of Computer Assisted Learning, 17(3), 235-241.

Vanderlinde, R. \& van Braak, J. (2010). The e-capacity of primary schools: Development of a conceptual model and scale construction from a school improvement perspective. Computers \& Education, 55, 541-553.

Wellman, B., Smith, A., Wells, A., \& Kennedy, T. (2008). Networked families. Washington, DC: Pew Internet \& American Life Project. Retrieved from http://www. pewinternet.org/Reports/2008/Networked-Families.aspx. 